\title{
Review Article \\ Recent Advances on Recursive Filtering and Sliding Mode Design for Networked Nonlinear Stochastic Systems: A Survey
}

\author{
Jun Hu, ${ }^{1}$ Zidong Wang, ${ }^{2,3}$ Hongli Dong, ${ }^{4,5}$ and Huijun Gao ${ }^{6}$ \\ ${ }^{1}$ Department of Applied Mathematics, Harbin University of Science and Technology, Harbin 150080, China \\ ${ }^{2}$ School of Information Science and Technology, Donghua University, Shanghai 200051, China \\ ${ }^{3}$ Department of Information Systems and Computing, Brunel University, Uxbridge, Middlesex UB8 3PH, UK \\ ${ }^{4}$ College of Electrical and Information Engineering, Northeast Petroleum University, Daqing 163318, China \\ ${ }^{5}$ Institute for Automatic Control and Complex Systems, University of Duisburg-Essen, Duisburg 47057, Germany \\ ${ }^{6}$ Research Institute of Intelligent Control and Systems, Harbin Institute of Technology, Harbin 150001, China
}

Correspondence should be addressed to Zidong Wang; zidong.wang@brunel.ac.uk

Received 22 September 2013; Accepted 18 October 2013

Academic Editor: Xiao He

Copyright (C) 2013 Jun Hu et al. This is an open access article distributed under the Creative Commons Attribution License, which permits unrestricted use, distribution, and reproduction in any medium, provided the original work is properly cited.

\begin{abstract}
Some recent advances on the recursive filtering and sliding mode design problems for nonlinear stochastic systems with networkinduced phenomena are surveyed. The network-induced phenomena under consideration mainly include missing measurements, fading measurements, signal quantization, probabilistic sensor delays, sensor saturations, randomly occurring nonlinearities, and randomly occurring uncertainties. With respect to these network-induced phenomena, the developments on filtering and sliding mode design problems are systematically reviewed. In particular, concerning the network-induced phenomena, some recent results on the recursive filtering for time-varying nonlinear stochastic systems and sliding mode design for time-invariant nonlinear stochastic systems are given, respectively. Finally, conclusions are proposed and some potential future research works are pointed out.
\end{abstract}

\section{Introduction}

In recent years, the networked control systems (NCSs) have become very prevalent owing to the advantage of decreasing the hard-wiring, the installation cost, and the implementation difficulties. Their applications could cover a wide range of industries such as space and terrestrial exploration, access in hazardous environments, factory automation, remote diagnostics and troubleshooting, experimental facilities, domestic robots, aircraft, automobiles and manufacturing plant monitoring $[1,2]$. In the networked world nowadays, signals are typically transmitted through networks (e.g., Internet) which may undergo unavoidable communication delays, packet dropouts and disorder, quantization, saturations, and so on. These network-induced phenomena include, but are not limited to, missing measurements, fading measurements, signal quantization, time-delays, randomly occurring nonlinearities, probabilistic sensor delays, and sensor saturations. It is well known that these network-induced phenomena would lead to abrupt structural and parametric changes in practical engineering applications. Consequently, it is of important significance to tackle the filtering and sliding mode design problems for systems with network-induced phenomena.

The nonlinearity and stochasticity are ubiquitous features existing in almost all practical systems that contribute significantly to the complexity of system modeling. Since the occurrence of the nonlinearities and stochasticity which inevitably degrades the system performance and even leads to instability, the analysis and synthesis problems for nonlinear stochastic systems have long been the main stream of research topics and much efforts have been made to deal with the nonlinear stochastic systems. Accordingly, many control and filtering approaches have been successfully applied in many branches of practical domains such as computer vision, communications, navigation and tracking systems, and econometrics and finance. Over the past decade, with the rapid developments of the NCSs, the design of controller and filter for nonlinear stochastic systems with network-induced 
phenomena has recently become a hot research focus that has attracted an increasing interest.

In this paper, we aim to provide a timely review on the recent advances of the recursive filtering and sliding mode design for nonlinear stochastic systems with network-induced phenomena. The network-induced phenomena under consideration include missing measurements, fading measurements, signal quantization, probabilistic sensor delays, sensor saturations, randomly occurring nonlinearities, and randomly occurring uncertainties. The recent developments of the network-induced phenomena are first summarized. Secondly, various filtering and sliding mode designs for nonlinear stochastic systems are reviewed in great detail and some interesting yet challenging issues are raised. Subsequently, latest results on recursive filtering and sliding mode design for discrete-time nonlinear stochastic systems with network-induced phenomena are reviewed. Finally, conclusions are drawn and some possible related research directions are pointed out.

The remainder of this paper is arranged as follows. In Section 2, the network-induced phenomena are discussed. In Section 3, the developments of filtering and sliding mode design problems for nonlinear stochastic systems are summarized. Some latest results on the recursive filtering and sliding mode design problems for nonlinear stochastic systems with network-induced phenomena are reviewed in Section 4. In Section 5, both the conclusions and some future research works are given.

\section{Network-Induced Phenomena}

Recently, much work has been done on the network-induced problems focusing on the missing measurements, fading measurements, signal quantization, sensor saturations, probabilistic sensor delays, randomly occurring nonlinearities, time delays, and so forth.

2.1. Missing Measurements. Most traditional controller/filter design approaches rely on the assumption that the measurement signals are perfectly transmitted. Such an assumption, however, is conservative in many engineering practices presented with unreliable communication channels. For example, due to temporal sensor failures or network congestions, the system measurements may contain noise only at certain time points and the true signals are simply missing. As such, the control and filtering problems with missing measurements have received considerable research attention and many important results have been reported in recent years; see, for example, [3-13]. To be more specific, the optimal estimation problems have been investigated in $[5,8]$ for linear systems with multiple packet dropouts. In [12], the stochastic stability has been analyzed for extended Kalman filtering (EKF) with intermittent observations. A common way for modeling the data missing is to introduce a random variable satisfying the Bernoulli binary distribution taking values on either 1 or 0 , where 1 is for the perfect signal delivery and 0 represents the measurement missing. Most of the aforementioned results have been based on the hypothesis that all sensors have identical failure characteristics [5]. However, in practical applications, owing to the sensors aging, sensor temporal failure, or some of the data coming from a highly noisy environment, the measurement missing might be partial and individual sensor could have different missing probability in the data transmission process [11].

2.2. Fading Measurements. Fading measurements are now well known to be one of the most frequently occurring phenomena in networked systems $[14,15]$. They refer to the cases when the perfect communication is not always available and the system measurement fades/degrades in a probabilistic way. To be specific, the linear state estimation problem has been investigated in [14], where single or multiple sensors amplify and forward their measurements of a common linear dynamical system to a remote fusion center via noisy fading wireless channels. It has been shown that the expected estimation error covariance (with respect to the fading process) at the fusion center remains bounded and converges to a steady state value. The estimation outage minimization problem has been studied in [15] for state estimation of linear systems over wireless fading channels. Obviously, the missing measurements mentioned above are extreme cases of the fading ones. Accordingly, the filtering problems with missing measurements have drawn considerable research interest $[5,12,16-$ 18]. Very recently, a more general description of the multiple missing measurements has been put forward in [11] and has already stirred some research interests where each sensor is allowed to have individual missing probability in data transmission. As mentioned above, a usual way for handling the missing measurements is to introduce the Bernoulli distributed white sequence specified by a conditional probability distribution, where the measurement signal is assumed to be either completely missing or completely available. However, such an assumption is quite restrictive in practice in case of fading measurements for an array of sensors.

2.3. Signal Quantization. At the forefront of networked system, the quantization issue has recently become a research focus that has attracted an increasing interest because, in a networked environment, signals are often quantized before being transmitted to other nodes due to the finite word length of the packets. Up to now, a series of results have been available in the literature on the quantization effects; see, for example, [19-25] and the references therein. In [21], the problem of quadratic stabilization has been studied for singleinput-single-output linear time-invariant systems with logarithmic quantizers. Subsequently, by using the sector-bound approach, the quantized feedback control problems have been tackled in $[23,26]$ for linear discrete-time systems. Parallel to the quantized feedback control issue, the quantized estimation problem also has a wide range of applications, see for example, [27, 28] for more detailed discussions. Specifically, in the case when the measured signals are transmitted over a digital communication channel, the state estimator has been designed in [28] for linear system with quantized measurements. It is worth noticing that most published results 
on the quantization effects have been dealt with for timeinvariant systems over an infinite horizon. However, in reality, the majority of practical systems exhibiting the time-varying nature and the system dynamics are better quantified over a finite horizon, and this is particularly true for systems undergoing digital discretization. So far, the finite-horizon recursive filtering problem has not been properly investigated for nonlinear time-varying systems subject to quantization effects.

\subsection{Randomly Occurring Nonlinearities and Randomly Occur-} ring Uncertainties. Nonlinearities and uncertainties serve as two important kinds of complexities for system modeling. As is well known, many engineering systems in practice are influenced by additive nonlinear disturbances and/or uncertainties that are caused by environmental circumstances. Such unpredictable disturbances may be subject to random abrupt variations, for instance, random failures and repairs of components, changing subsystem interconnections, sudden environmental disturbances, and modification of the operating point of a linearized model of a nonlinear system. In other words, the nonlinear disturbances and the parameter uncertainties may occur in a probabilistic way with certain types and intensity. A typical example is the networked control systems where signals are transmitted through networks and the nonlinear disturbances and the uncertainties may occur according to the network conditions that are randomly changeable. In this case, both the randomly occurring nonlinearities (RONs) and the randomly occurring uncertainties (ROUs) should be taken into account when designing the practical control systems. Recently, in $[29,30]$, the concept of RONs has been introduced to model the randomly occurring nonlinear functions for complex networks, but ROUs has not yet received adequate research attention.

\subsection{Probabilistic Sensor Delays. Most traditional filtering} algorithms have been based on the measurement outputs that are supposed to contain information about the current state of the system. However, in engineering practice, the system measurements may be subject to unavoidable sensor delays, which is particularly true in a networked environment. In the past decade, a great number of results have been reported for filtering problems with deterministic/fixed sensor delays; see for example, [31-33]. On the other hand, because of limited bandwidth of the communication channel, it is often the case that the sensor delay occurs in a random way when, for example, the information is transmitted through networks in realtime distributed decision-making and multiplexed data communication environment [34]. Accordingly, the filtering problems with random sensor delays have recently received much research attention (see, e.g., [35-39]), where all sensors share the same type of delay characteristics $[40,41]$. Nevertheless, in reality, the system measurements are usually collected through multiple sensors with different physical constraints. In this case, it is fairly conservative to assume that all sensors undergo random delays of the same probability distribution law. Rather, it would make more practical sense to consider individual features for randomly occurring sensor delays.
2.6. Sensor Saturations. It is well known that sensors may not always produce signals of unlimited amplitude mainly due to the physical constraints or technological restrictions. The sensor saturation, if not properly handled, will inevitably affect the implementation precision of the designed filtering/ control algorithms and may even cause undesirable degradation of the filter/controller performance. Consequently, the actuator/sensor saturation problem has been gaining an increasing research interest that has led to many important results reported in the recent literature; see, for example, [4248]. To be more specific, the output feedback $H_{\infty}$ controllers have been synthesized in $[43,47,48]$ and the robust $H_{\infty}$ filters have been designed in $[44,45]$ for systems with sensor saturations. It is worth mentioning that most existing results concerning the sensor saturations have been concerned with time-invariant systems over the infinite-horizon. Unfortunately, in reality, almost all real-time systems should be timevarying especially those after digital discretization. Recently, motivated by the practical importance of the sensor saturation issues, the $H_{\infty}$ control problem has been addressed in [48] and the set-membership filtering problem has been investigated in [46] for a class of time-varying systems with saturated sensors.

2.7. Random Parameter Matrices. Discrete-time systems with random parameter matrices arise in many application domains such as digital control of chemical processes, mobile robot localization, radar control, missile track estimation, navigation systems, and economic systems [49-51]. For this case, some system parameters might be randomly perturbed within certain intervals probably due to the abrupt phenomena such as random failures and repairs of the components, changes in the interconnections of subsystems, sudden environment changes, and modification of the operating point of a linearized model of nonlinear systems. Accordingly, some research efforts have been made on the filter design with random parameter matrices. For example, the recursive optimal estimation problem has been dealt with in [49] for linear discrete-time systems with random parameter matrices in the minimum variance sense. The distributed Kalman filtering fusion problem has been tackled in [50] for systems with random parameter matrices and the potential application has also been discussed. Nevertheless, probably due to its mathematical complexity, the recursive filtering problem for discrete time-varying nonlinear stochastic systems with random parameter matrices has not received adequate research attention yet.

2.8. Time Delays. It is well known that time-delays are frequently encountered in many industrial and engineering systems (e.g., chemical process, long transmission lines in pneumatic, and communication networks) due to the finite switching speed of amplifiers or finite speed of information processing $[52,53]$. The existence of time delays may cause undesirable dynamic behaviors such as oscillation and instability $[54,55]$. Over the past decades, much effort has been made to address the time-delay systems; see, for example, [56-64] and references cited therein. To mention a few, a sliding surface 
has been constructed in [57] for the uncertain system with single/multiple state-delays and additive perturbations. In [58], by means of linear matrix inequality (LMI) technique, an integral sliding mode surface has been designed to address the sliding mode control (SMC) problem for the uncertain stochastic system with time-varying delays. In the case when the system states are not easily measured, the SMC problem has been investigated in [59] for systems with mismatched uncertainties via the output feedback approach. In [65], the SMC problem has been investigated for a class of nonlinear singular stochastic systems with Markovian switching. Actually, according to the occurrence way of time-delays, the timedelays can be generally classified into two types: discrete delays and distributed delays. Most of results mentioned above are applicable to continuous-time systems only, and the relevant results for discrete-time systems with mixed (i.e., both discrete and distributed) delays have been very few. The distributed time-delay in the discrete-time setting is an emerging concept that has been proposed in $[30,66]$ for complex networks.

\section{Recursive Filtering and Sliding Mode Design for Nonlinear Stochastic Systems}

In this section, we are in a position to review the approaches for handling the recursive filtering and sliding mode design problems for nonlinear stochastic systems.

3.1. Recursive Filter Design. The analysis and synthesis problems for nonlinear systems have been the mainstream of research topics and much effort has been made to deal with the nonlinear stochastic systems; see, for example, [11, 67-81]. It is worth pointing out that, in most literature, the nonlinearities are assumed to occur in a deterministic way. While this assumption is generally true especially for systems modeled according to physical laws, other kinds of nonlinearities, namely, stochastic nonlinearities, deserve particular research attention since they occur randomly probably due to intermittent network congestion, random failures and repairs of the components, changes in the interconnections of subsystems, sudden environment changes, and modification of the operating point of a linearized model of nonlinear systems. In fact, such stochastic nonlinearities include the state-multiplicative noises and random sequences as special cases. Recently, the filtering problem with stochastic nonlinearities described by statistical means has already stirred some research interests, and some latest results can be found in $[11,73,82]$ and the references therein.

In the past few decades, the filtering or state estimation problems for stochastic systems have been extensively investigated and successfully applied in many branches of practical domains [83-86]. It is well known that the traditional Kalman filter (KF) serves as an optimal filter in the least mean square sense for linear systems with the assumption that the system model is exactly known. In the case when the system model is nonlinear and/or uncertain, there has been an increasing research effort to improve Kalman filters with hope to enhance their capabilities of handling nonlinearities and uncertainties.
Along this direction, many alternative filtering schemes have been reported in the literature including the $H_{\infty}$ filtering [8789], mixed $H_{2} / H_{\infty}$ filtering [90-92], and robust EKF design [93-97]. To mention a few, the optimal linear estimation problems have been intensively studied in [9] with multiple packet dropouts and in [40] for multiple sensors with different delay rates, the robust recursive KF algorithm has been developed in [98] for linear time-varying systems with stochastic parametric uncertainties, and the EKF problem has been dealt with in [94] for a class of uncertain systems with sum quadratic constraints. Note that almost all real-time systems are time-varying and therefore finite-horizon filtering problem is of practical significance [99]. However, there have been very few results in the literature regarding filtering problems over a finite horizon for time-varying nonlinear stochastic systems with network-induced phenomena.

In most of the available filtering algorithms, a conservative assumption is that the process and measurement noises are uncorrelated. In practical engineering, these two kinds of noises are often correlated. For example, for the target tracking problem, there may exists the cross correlation between the process noise and the measurement noise if both of them are dependent on the system state. Also, the process noise sequences of a discrete-time system sampled from a continuous-time system are inherently correlated across time, and there may be cross correlation between different sensor noises if the various sensors work in a common noisy environment. A typical example is the radar systems whose sampling frequency is high enough compared with the error bandwidth [100]. Recently, the filter design problems have been widely studied in [101-106] with autocorrelated noises and/or cross correlated noises. It should be mentioned that very little research effort has been made on the recursive filtering problem for time-varying nonlinear stochastic systems with correlated noises and network-induced phenomena.

For practical purposes, the filter design is inevitably subject to certain physical constraints. For example, in many applications, the system states should preserve the positivity, the system outputs experience saturations, and the filter gains may need to be of a specific structure for easy implementation. It should be pointed out that the filtering problems with constraints have been gaining a recurring research interest in the past decade; see, for example, [103, 107-111]. Very recently, in [110], a KF algorithm has been developed to cope with the constraints on the data injection gain. The gain-constrained filtering problem has been investigated for a broad class of real-time dynamical systems; see, for example, the tracking problem of a land based vehicle [103], the estimation problem of two state continuous stirred tank reactor [112], and the tracking problem of a vehicle along circular roads [113].

3.2. Probability Guaranteed $H_{\infty}$ Filter Design. In traditional control theory, the performance objectives of a controlled system are usually required to be met accurately [114]. However, for many stochastic control problems, due to a variety of unpredictable disturbances, it is neither possible nor necessary to enforce the system performance with probability 1 . Instead, it is quite common for practical control systems to 
attain their individual performance objective with certain satisfactory probability. These kinds of engineering problems have given rise to great challenges for the realization of multiple control objectives with respect to individual probability constraints. In particular, as a newly emerged research topic, the probability-guaranteed $H_{\infty}$ controller design problem has been raised in [115] and then thoroughly investigated in [116-119] in an elegant way. Specifically, the probability-guaranteed $H_{\infty}$ analysis problem has been studied in $[115,119]$ for a class of linear continuous-time systems and in [116] for a class of linear discrete-time systems with structured disturbances. Recently, a new probability-guaranteed robust $H_{\infty}$ filtering problem has been put forward in [118] for a class of linear continuous time-invariant systems. Despite the advances made on the research topic of probability-guaranteed design, there is still much room for further investigation on more comprehensive systems in order to cover more engineering practice. For example, in reality, most engineering systems are nonlinear and time-varying with saturated sensors, where the performances are usually evaluated over a finite-horizon for time-varying systems.

3.3. Sliding Mode Controller/Observer Design. Among various design methods for robust control, the sliding mode control (SMC) scheme appears to be a rather popular one that has been extensively studied and widely applied. This is because SMC possesses remarkable strong robustness against model uncertainties, parameter variations, and external disturbances $[65,120-122]$. In the past two decades, SMC has become one of the most active branches of control theory that has found successful applications in a variety of practical engineering systems such as robot manipulators, aircrafts, underwater vehicles, spacecrafts, electrical motors, positioning systems, and automotive engines. For example, the adaptive sliding mode has been studied in $[123,124]$ for sensorless motor drives. The effective SMC schemes have been designed in [125] for high-speed positioning systems and in [126] for spacecraft-attitude-tracking maneuvers. Also, considerable research attention has been devoted to the theoretical research on SMC problems for different systems. For example, the concept of SMC has been widely employed in controller design problems for uncertain systems [61, 127, $128]$, stochastic systems $[58,59,65,129]$, and Markovian jump systems $[65,130]$.

Recently, many important results have been reported on the SMC problem for discrete-time systems; see [60, 61, 131$135]$. In $[136,137]$, the SMC problems for a class of uncertain systems with mismatched uncertainty have been investigated. In the context of SMC for discrete-time systems, the quasisliding mode concept has been proposed in [133] and the discrete-time sliding mode reaching condition has been thoroughly studied based on a reaching law approach. Such a reaching condition has recently been shown in $[60,61,138-$ 140 ] to be a popular and convenient way of addressing the SMC problems for a class of discrete-time systems. Noting the advantages of the NCSs, it seems significantly important to investigate the SMC problem for discrete-time system with various network-induced phenomena.
On the other hand, it is well known that system states are not always available mainly due to the limit of physical conditions or expense for measuring in reality. Therefore, the state estimation problem has received a great deal of research attention. In recent years, the sliding mode observer (SMO) theory has been successfully applied to a wide range of areas such as induction motor drives, $n$-degree-of-freedom mechanical systems, and single-link flexible joint robot systems [141-143]. When designing the sliding mode observers (SMOs), a suitable nonlinear output injection is usually introduced to guarantee finite time convergence and induce a sliding motion. Most research on SMO design has been carried out along this line; see, for example, [141, 142, 144-149]. To be specific, by constructing an appropriate SMO, the fault reconstruction and estimation problems have been extensively studied in $[143,146-148,150]$ for uncertain systems. It should be pointed out that almost all results mentioned above have been concerned with continuous-time systems, and the relevant results for discrete-time systems have been very few despite the fact that nowadays digitalized control systems are inherently discrete-time ones.

As mentioned above, the time-delays and nonlinearities are inevitably encountered in various industrial systems. The occurrence of time-delays and nonlinearities would cause great degradation of the system performance. Accordingly, the SMO problem for nonlinear and/or time-delay systems has gained considerable research interest and a variety of important results have been published in the literature; see $[143,148,150-152]$. To mention a few, in [151], an $H_{\infty} \mathrm{SMO}$ problem has been investigated for uncertain nonlinear Lipschitz-type systems with fault and disturbances and a sufficient condition has been given such that the $H_{\infty}$ performance requirement is satisfied. By using Taylor series expansion and employing a nonlinear transformation, the discrete-time model has been derived in $[150,152]$ from its continuous-time counterpart and then the discrete-time sliding mode state estimation problems have been addressed for uncertain nonlinear systems. So far, very few results have been available for the SMO problem of discrete-time systems with time-delays.

\section{Latest Progress}

Very recently, the recursive filtering and sliding mode design problems have been widely investigated for nonlinear stochastic systems with network-induced phenomena and some interesting results have been reported. In this section, some of the newest works with respect to this topic are summarized.

(i) In $[153,154]$, the recursive filtering problems have been investigated for two classes of time-varying nonlinear stochastic systems. Firstly, the phenomenon of measurement missing occurs in a random way and the missing probability for each sensor is governed by an individual random variable satisfying a certain probability distribution over the interval $[0,1]$. Such a probability distribution is allowed to be any commonly used distribution over the interval $[0,1]$ with known conditional probability. Both deterministic and stochastic nonlinearities have been included in the system model, where the stochastic nonlinearities have been 
described by statistical means that could reflect the multiplicative stochastic disturbances. A new filter has been first designed in [153] such that, in the presence of both the stochastic nonlinearities and multiple missing measurements, there exists an upper bound for the filtering error covariance which is minimized by properly designing the filter gain. Secondly, the recursive finite-horizon filtering problem has been investigated in [154] for a class of time-varying nonlinear systems subject to multiplicative noises, missing measurements, and quantization effects. The missing measurements have been modeled by a series of mutually independent random variables obeying Bernoulli distributions with possibly different occurrence probabilities. The quantization phenomenon has been described by using the logarithmic function and the multiplicative noises have been considered to account for the stochastic disturbances on the system states. By using similar techniques, the desired filter parameters have been obtained by solving two Riccati-like difference equations that are of a recursive form suitable for online applications.

(ii) In $[155,156]$, the recursive filtering problems have been studied for two classes of time-varying stochastic systems with stochastic nonlinearities. Firstly, the phenomenon of measurement fading occurs in a random way and the fading probability for each sensor is governed by an individual random variable obeying a certain probability distribution over the known interval $\left[\beta_{k}, \gamma_{k}\right]$. Such a probability distribution could be any commonly used discrete distribution over the interval $\left[\beta_{k}, \gamma_{k}\right]$ that covers the Bernoulli distribution as a special case. The process noise and the measurement noise are one-step autocorrelated, respectively. The process noise and the measurement noise are two-step cross correlated. An unbiased, recursive and locally optimal filter has been designed in [155] for a class of time-varying nonlinear stochastic systems with random parameter matrices, stochastic nonlinearity, and multiple fading measurements as well as correlated noises. Secondly, the proposed filtering method has been extended to deal with the gain-constrained recursive filter design problem in [156] for the systems subject to probabilistic sensor delays, stochastic nonlinearities, and finite-step correlated noises. Intensive stochastic analysis has been carried out to obtain the filter gain characterized by the solution to recursive matrix equations. It has been shown that the proposed scheme is of a form suitable for recursive computation in online applications.

(iii) The probability-guaranteed $H_{\infty}$ finite-horizon filtering problem has been discussed in [157] for a class of timevarying nonlinear systems with uncertain parameters and sensor saturations. The system matrices are functions of mutually independent stochastic variables that obey uniform distributions over known finite ranges. By using the sectorbounded approach, a decomposition technique has been employed to facilitate the filter design in terms of difference linear matrix inequalities (DLMIs). Attention has been focused on the construction of a time-varying filter such that the prescribed $H_{\infty}$ performance requirement can be guaranteed with prespecified probability constraint. By employing the DLMIs approach, sufficient conditions have been established to guarantee the desired performance of the designed finite-horizon filter. The time-varying filter gains have been obtained in terms of the feasible solutions to a set of DLMIs that can be recursively solved by using the semidefinite programming method. A computational algorithm has been specifically developed for the addressed probability-guaranteed $H_{\infty}$ finite-horizon filtering problem.

(iv) The $H_{\infty}$ SMO design problem has been studied in [158] for a class of nonlinear discrete time-delay systems. The nonlinear descriptions quantify the maximum possible derivations from a linear model and the system states are allowed to be immeasurable. Attention has been focused on the design of a discrete-time SMO such that the asymptotic stability as well as the $H_{\infty}$ performance requirement of the error dynamics can be guaranteed in the presence of nonlinearities, time-delay, and external disturbances. Firstly, a discrete-time discontinuous switched term has been constructed to make sure that the reaching condition holds. Then, by constructing a new Lyapunov-Krasovskii functional based on the idea of "delay-fractioning" and introducing some appropriate freeweighting matrices, a sufficient condition has been established to guarantee the desired performance of the error dynamics in the specified sliding surface by solving a minimization problem. In particular, the so-called "weighting" scalar parameters have been constructively introduced to fit both the delay-fractioning idea and the sliding mode approach. It has been shown that the desired observer gains can be obtained in terms of the feasible solutions to a set of matrix inequalities that can be solved easily by using the semidefinite programming method.

(v) In $[159,160]$, the robust SMC problems have been investigated for discrete-time uncertain nonlinear stochastic systems with time-varying delays. Firstly, the randomly occurring nonlinearity (RON), which describes the phenomenon of a class of nonlinear disturbances occurring in a random way, has been modeled according to a Bernoulli distributed white sequence with a known conditional probability. By constructing a novel Lyapunov-Krasovskii functional, the idea of delay-fractioning has been applied to cope with the robust SMC problem with time-delays. Sufficient conditions have been derived in [159] to ensure the stability of the systems dynamics in the specified sliding surface. Such conditions have been characterized in terms of a set of LMIs with an equality constraint. A new discrete-time SMC law has been synthesized to guarantee the reaching condition of the discrete-time sliding surface. Moreover, the robust $H_{\infty}$ SMC problem has been investigated in [160] for a general class of discrete-time uncertain systems with stochastic nonlinearities and time-varying delays. By constructing a similar sliding surface and designing the SMC law, sufficient conditions have been given to ensure that, for all parameter uncertainties, unmatched stochastic nonlinearities, time-varying delays, and unmatched external disturbance, the sliding mode dyna mics is asymptotically mean-square stable while achieving a prescribed disturbance attenuation level.

(vi) In $[161,162]$, the robust SMC problems have been studied for discrete-time uncertain nonlinear stochastic systems with mixed time-delays. Firstly, both the sector-like nonlinearities and the norm-bounded uncertainties enter into the system in random ways, and such ROUs and RONs 
obey certain mutually uncorrelated Bernoulli distributed white noise sequences with known conditional probabilities. This description can reflect the fact that the ROUs and RONs can appear or disappear in a probabilistic way due to unpredictable changes of the environmental circumstances. The mixed time-delays consist of both the discrete and the distributed delays, and the stochastic disturbance is of the general Itô-type. An SMC law has been designed in [161] such that the mean-square asymptotic stability of the sliding mode dynamics can be guaranteed in the presence of ROUs and RONs as well as mixed time-delays. By employing the idea of delay-fractioning and constructing a new Lyapunov-Krasovskii functional, sufficient conditions have been established to achieve the desired performance in the specified sliding surface by solving certain semidefinite programming problem. Secondly, the robust SMC design problem has been investigated in [162] for a class of uncertain nonlinear systems with Markovian jumping parameters and mixed time-delays, and a set of parallel results has been derived.

\section{Conclusions and Future Works}

In this paper, we have summarized some recent advances on the recursive filtering and sliding mode design for nonlinear stochastic systems with network-induced phenomena. The developments of the network-induced phenomena have been surveyed. Subsequently, various recursive filtering and sliding mode design problems have been discussed for nonlinear stochastic systems. Furthermore, the recursive filtering and sliding mode design approaches of the nonlinear stochastic systems with network-induced phenomena have been given and the latest results have been reviewed. To conclude this survey paper, we highlight some related topics for the further research works as follows.

(i) The nonlinearities addressed have some constraints that may bring somewhat conservative results. The analysis and synthesis of more general nonlinear systems with network-induced phenomena would be one of the future research topics.

(ii) Another future research direction is to investigate the guaranteed-cost control problem for nonlinear timevarying systems with randomly occurring actuator failures over a finite time-horizon.

(iii) In case that the convergence analysis of the recursive filter approach becomes a concern, some additional assumptions can be made on the system parameters in order to ensure the global boundedness of the estimation errors, which constitutes one of the future research topics.

(iv) When the system states are immeasurable, the dynamic output feedback sliding mode design is desired for time-delay nonlinear stochastic systems with network-induced phenomena.

(v) An additional trend for future research is to generalize the current methods to the synchronization, control, and filtering problems for nonlinear stochastic complex networks with network-induced phenomena.

\section{Acknowledgments}

This work was supported in part by the National Natural Science Foundation of China under Grant nos. 61134009, 61329301, 61333012, 61374127 and 11301118, the Engineering and Physical Sciences Research Council (EPSRC) of the UK under Grant no. GR/S27658/01, the Royal Society of the UK, and the Alexander von Humboldt Foundation of Germany.

\section{References}

[1] H. Dong, Z. Wang, X. Chen, and H. Gao, "A review on analysis and synthesis of nonlinear stochastic systems with randomly occurring incomplete information," Mathematical Problems in Engineering, vol. 2012, Article ID 416358, 15 pages, 2012.

[2] B. Shen, Z. Wang, J. Liang, and Y. Liu, "Recent advances on filtering and control for nonlinear stochastic complex systems with incomplete information: a survey," Mathematical Problems in Engineering, vol. 2012, Article ID 530759, 16 pages, 2012.

[3] H. Dong, Z. Wang, and H. Gao, "Observer-based $H_{\infty}$ control for systems with repeated scalar nonlinearities and multiple packet losses," International Journal of Robust and Nonlinear Control, vol. 20, no. 12, pp. 1363-1378, 2010.

[4] H. Dong, Z. Wang, D. W. C. Ho, and H. Gao, "Variance-constrained $H_{\infty}$ filtering for a class of nonlinear time-varying systems with multiple missing measurements: the finite-horizon case," IEEE Transactions on Signal Processing, vol. 58, no. 5, pp. 2534-2543, 2010.

[5] F. O. Hounkpevi and E. E. Yaz, "Robust minimum variance linear state estimators for multiple sensors with different failure rates," Automatica, vol. 43, no. 7, pp. 1274-1280, 2007.

[6] M. Sahebsara, T. Chen, and S. L. Shah, "Optimal $H_{\infty}$ filtering in networked control systems with multiple packet dropouts," Systems \& Control Letters, vol. 57, no. 9, pp. 696-702, 2008.

[7] M. Moayedi, Y. K. Foo, and Y. C. Soh, "Adaptive Kalman filtering in networked systems with random sensor delays, multiple packet dropouts and missing measurements," IEEE Transactions on Signal Processing, vol. 58, no. 3, pp. 1577-1588, 2010.

[8] S. Sun, L. Xie, W. Xiao, and Y. C. Soh, "Optimal linear estimation for systems with multiple packet dropouts," Automatica, vol. 44, no. 5, pp. 1333-1342, 2008.

[9] S. Sun, L. Xie, W. Xiao, and N. Xiao, "Optimal filtering for systems with multiple packet dropouts," IEEE Transactions on Circuits and Systems II, vol. 55, no. 7, pp. 695-699, 2008.

[10] Z. Wang, D. W. C. Ho, and X. Liu, "Variance-constrained filtering for uncertain stochastic systems with missing measurements," Institute of Electrical and Electronics Engineers, vol. 48, no. 7, pp. 1254-1258, 2003.

[11] G. Wei, Z. Wang, and H. Shu, "Robust filtering with stochastic nonlinearities and multiple missing measurements," Automatica, vol. 45, no. 3, pp. 836-841, 2009.

[12] S. Kluge, K. Reif, and M. Brokate, "Stochastic stability of the extended Kalman filter with intermittent observations," IEEE Transactions on Automatic Control, vol. 55, no. 2, pp. 514-518, 2010.

[13] X. He, Z. Wang, X. Wang, and D. Zhou, "Networked strong tracking filtering with multiple packet dropouts: algorithms and applications," IEEE Transactions on Industrial Electronics, vol. 61, no. 3, pp. 1454-1463, 2014.

[14] S. Dey, A. S. Leong, and J. S. Evans, "Kalman filtering with faded measurements," Automatica, vol. 45, no. 10, pp. 2223-2233, 2009. 
[15] A. S. Leong, S. Dey, G. N. Nair, and P. Sharma, "Power allocation for outage minimization in state estimation over fading channels," IEEE Transactions on Signal Processing, vol. 59, no. 7, pp. 3382-3397, 2011.

[16] B. Sinopoli, L. Schenato, M. Franceschetti, K. Poolla, M. I. Jordan, and S. S. Sastry, "Kalman filtering with intermittent observations," IEEE Transactions on Automatic Control, vol. 49, no. 9, pp. 1453-1464, 2004.

[17] Z. Wang, F. Yang, D. W. C. Ho, and X. Liu, "Robust $H_{\infty}$ filtering for stochastic time-delay systems with missing measurements," IEEE Transactions on Signal Processing, vol. 54, no. 7, pp. 25792587, 2006.

[18] M. Sahebsara, T. Chen, and S. L. Shah, "Optimal $H_{2}$ filtering in networked control systems with multiple packet dropout," IEEE Transactions on Automatic Control, vol. 52, no. 8, pp. 1508-1513, 2007.

[19] Z. Wang, H. Dong, B. Shen, and H. Gao, "Finite-horizon $H_{\infty}$ filtering with missing measurements and quantization effects," IEEE Transactions on Automatic Control, vol. 58, no. 7, pp. 17071718, 2013.

[20] R. W. Brockett and D. Liberzon, "Quantized feedback stabilization of linear systems," IEEE Transactions on Automatic Control, vol. 45, no. 7, pp. 1279-1289, 2000.

[21] N. Elia and S. K. Mitter, "Stabilization of linear systems with limited information," IEEE Transactions on Automatic Control, vol. 46, no. 9, pp. 1384-1400, 2001.

[22] M. L. Corradini and G. Orlando, "Robust quantized feedback stabilization of linear systems," Automatica, vol. 44, no. 9, pp. 2458-2462, 2008.

[23] M. Fu and L. Xie, "The sector bound approach to quantized feedback control," IEEE Transactions on Automatic Control, vol. 50, no. 11, pp. 1698-1711, 2005.

[24] W. P. M. H. Heemels, A. R. Teel, N. van de Wouw, and D. Nešić, "Networked control systems with communication constraints: tradeoffs between transmission intervals, delays and performance," IEEE Transactions on Automatic Control, vol. 55, no. 8, pp. 1781-1796, 2010.

[25] Z. Wang, B. Shen, H. Shu, and G. Wei, "Quantized $H_{\infty}$ control for nonlinear stochastic time-delay systems with missing measurements," IEEE Transactions on Automatic Control, vol. 57, no. 6, pp. 1431-1444, 2012.

[26] D. F. Coutinho, M. Fu, and C. E. de Souza, "Input and output quantized feedback linear systems," IEEE Transactions on Automatic Control, vol. 55, no. 3, pp. 761-766, 2010.

[27] R. Carli, F. Fagnani, P. Frasca, and S. Zampieri, "A probabilistic analysis of the average consensus algorithm with quantized communication," in Proceedings of the 17th World Congress, International Federation of Automatic Control (IFAC'08), Seoul, Korea, July 2008.

[28] M. Fu and C. E. de Souza, "State estimation for linear discretetime systems using quantized measurements," Automatica, vol. 45, no. 12, pp. 2937-2945, 2009.

[29] Y. Wang, Z. Wang, and J. Liang, "Global synchronization for delayed complex networks with randomly occurring nonlinearities and multiple stochastic disturbances," Journal of Physics A, vol. 42, no. 13, article 135101, 2009.

[30] Z. Wang, Y. Wang, and Y. Liu, "Global synchronization for discrete-time stochastic complex networks with randomly occurred nonlinearities and mixed time delays," IEEE Transactions on Neural Networks, vol. 21, no. 1, pp. 11-25, 2010.
[31] H. Zhang, G. Feng, G. Duan, and X. Lu, " $H_{\infty}$ filtering for multiple-time-delay measurements," IEEE Transactions on Signal Processing, vol. 54, no. 5, pp. 1681-1688, 2006.

[32] M. Basin, M. A. Alcorta-Garcia, and A. Alanis-Duran, "Optimal filtering for linear systems with state and multiple observation delays," International Journal of Systems Science, vol. 39, no. 5, pp. 547-555, 2008.

[33] M. Basin, P. Shi, and D. Calderon-Alvarez, "Joint state filtering and parameter estimation for linear stochastic time-delay systems," Signal Processing, vol. 91, no. 4, pp. 782-792, 2011.

[34] F. Yang, Z. Wang, G. Feng, and X. Liu, "Robust filtering with randomly varying sensor delay: the finite-horizon case," IEEE Transactions on Circuits and Systems I, vol. 56, no. 3, pp. 664672, 2009.

[35] Y. I. Yaz and E. E. Yaz, "A new formulation of some discrete-time stochastic-parameter state estimation problems," Applied Mathematics Letters, vol. 10, no. 6, pp. 13-19, 1997.

[36] R. Caballero-Águila, A. Hermoso-Carazo, J. D. Jiménez-López, J. Linares-Pérez, and S. Nakamori, "Recursive estimation of discrete-time signals from nonlinear randomly delayed observations," Computers \& Mathematics with Applications, vol. 58, no. 6, pp. 1160-1168, 2009.

[37] J. Linares-Pérez, A. Hermoso-Carazo, R. Caballero-Águila, and J. D. Jiménez-López, "Least-squares linear filtering using observations coming from multiple sensors with one- or two-step random delay," Signal Processing, vol. 89, no. 10, pp. 2045-2052, 2009.

[38] M. Chen, "Synchronization in complex dynamical networks with random sensor delay," IEEE Transactions on Circuits and Systems II, vol. 57, no. 1, pp. 46-50, 2010.

[39] J. Ma and S. Sun, "Optimal linear estimators for systems with random sensor delays, multiple packet dropouts and uncertain observations," IEEE Transactions on Signal Processing, vol. 59, no. 11, pp. 5181-5192, 2011.

[40] F. O. Hounkpevi and E. E. Yaz, "Minimum variance generalized state estimators for multiple sensors with different delay rates," Signal Processing, vol. 87, no. 4, pp. 602-613, 2007.

[41] R. Caballero-Águila, A. Hermoso-Carazo, J. D. Jiménez-López, J. Linares-Pérez, and S. Nakamori, "Signal estimation with multiple delayed sensors using covariance information," Digital Signal Processing, vol. 20, no. 2, pp. 528-540, 2010.

[42] D. Chen, S. Li, and Y. Shi, "The practical stabilization for a class of networked systems with actuator saturation and input additive disturbances," Mathematical Problems in Engineering, vol. 2012, Article ID 326876, 19 pages, 2012.

[43] Y.-Y. Cao, Z. Lin, and B. M. Chen, "An output feedback $H_{\infty}$ controller design for linear systems subject to sensor nonlinearities," IEEE Transactions on Circuits and Systems I, vol. 50, no. 7, pp. 914-921, 2003.

[44] Y. Niu, D. W. C. Ho, and C. W. Li, "Filtering for discrete fuzzy stochastic systems with sensor nonlinearities," IEEE Transactions on Fuzzy Systems, vol. 18, no. 5, pp. 971-978, 2010.

[45] Y. Niu, D. W. C. Ho, and C. W. Li, " $H_{\infty}$ filtering for uncertain stochastic systems subject to sensor nonlinearities," International Journal of Systems Science, vol. 42, no. 5, pp. 737-749, 2011.

[46] F. Yang and Y. Li, "Set-membership filtering for systems with sensor saturation," Automatica, vol. 45, no. 8, pp. 1896-1902, 2009.

[47] Z. Zuo, J. Wang, and L. Huang, "Output feedback $H_{\infty}$ controller design for linear discrete-time systems with sensor nonlinearities," IEE Proceedings on Control Theory \& Applications, vol. 152, no. 1, pp. 19-26, 2005. 
[48] Z. Wang, D. W. C. Ho, H. Dong, and H. Gao, "Robust $H_{\infty}$ finitehorizon control for a class of stochastic nonlinear time-varying systems subject to sensor and actuator saturations," IEEE Transactions on Automatic Control, vol. 55, no. 7, pp. 1716-1722, 2010.

[49] W. L. De Koning, "Optimal estimation of linear discrete-time systems with stochastic parameters," Automatica, vol. 20, no. 1, pp. 113-115, 1984.

[50] Y. Luo, Y. Zhu, D. Luo, J. Zhou, E. Song, and D. Wang, "Globally optimal multisensor distributed random parameter matrices Kalman filtering fusion with applications," Sensors, vol. 8, no. 12, pp. 8086-8103, 2008.

[51] E. Yaz and R. E. Skelton, "Parametrization of all linear compensators for discrete-time stochastic parameter systems," Automatica, vol. 30, no. 6, pp. 945-955, 1994.

[52] S. Elmadssia, K. Saadaoui, and M. Benrejeb, "New delay-dependent stability conditions for linear systems with delay," Systems Science and Control Engineering, vol. 1, no. 1, pp. 2-11, 2013.

[53] Y. Chen and K. A. Hoo, "Stability analysis for closed-loop management of a reservoir based on identification of reduced-ordernonlinear model," Systems Science and Control Engineering, vol. 1, no. 1, pp. 12-19, 2013.

[54] H. Gao, Z. Fei, J. Lam, and B. Du, "Further results on exponential estimates of Markovian jump systems with mode-dependent time-varying delays," IEEE Transactions on Automatic Control, vol. 56, no. 1, pp. 223-229, 2011.

[55] H. Gao, Y. Zhao, and W. Sun, "Input-delayed control of uncertain seat suspension systems with human-body model," IEEE Transactions on Control Systems Technology, vol. 18, no. 3, pp. 591-601, 2010.

[56] E. Fridman, U. Shaked, and L. Xie, "Robust $H_{\infty}$ filtering of linear systems with time delays," International Journal of Robust and Nonlinear Control, vol. 13, no. 10, pp. 983-1010, 2003.

[57] F. Gouaisbaut, M. Dambrine, and J. P. Richard, "Robust control of delay systems: a sliding mode control design via LMI," Systems \& Control Letters, vol. 46, no. 4, pp. 219-230, 2002.

[58] Y. Niu, D. W. C. Ho, and J. Lam, "Robust integral sliding mode control for uncertain stochastic systems with time-varying delay," Automatica, vol. 41, no. 5, pp. 873-880, 2005.

[59] Y. Niu and D. W. C. Ho, "Robust observer design for Itô stochastic time-delay systems via sliding mode control," Systems \& Control Letters, vol. 55, no. 10, pp. 781-793, 2006.

[60] Y. Xia, G. P. Liu, P. Shi, J. Chen, D. Rees, and J. Liang, "Sliding mode control of uncertain linear discrete time systems with input delay," IET Control Theory \& Applications, vol. 1, no. 4, pp. 1169-1175, 2007.

[61] M. Yan and Y. Shi, "Robust discrete-time sliding mode control for uncertain systems with time-varying state delay," IET Control Theory \& Applications, vol. 2, no. 8, pp. 662-674, 2008.

[62] Z. Wang and D. W. C. Ho, "Filtering on nonlinear time-delay stochastic systems," Automatica, vol. 39, no. 1, pp. 101-109, 2003.

[63] Z. Wang, D. W. C. Ho, Y. Liu, and X. Liu, "Robust $H_{\infty}$ control for a class of nonlinear discrete time-delay stochastic systems with missing measurements," Automatica, vol. 45, no. 3, pp. 684-691, 2009.

[64] Z. Wang, J. Lam, and X. Liu, "Filtering for a class of nonlinear discrete-time stochastic systems with state delays," Journal of Computational and Applied Mathematics, vol. 201, no. 1, pp. 153163, 2007.

[65] L. Wu and D. W. C. Ho, "Sliding mode control of singular stochastic hybrid systems," Automatica, vol. 46, no. 4, pp. 779-783, 2010 .
[66] Y. Liu, Z. Wang, J. Liang, and X. Liu, "Synchronization and state estimation for discrete-time complex networks with distributed delays," IEEE Transactions on Systems, Man, and Cybernetics B, vol. 38, no. 5, pp. 1314-1325, 2008.

[67] A. Mehrsai, H. R. Karimi, and K. D. Thoben, "Integration of supply networks for customization with modularity in cloudand make-to-upgrade strategy," Systems Science and Control Engineering, vol. 1, no. 1, pp. 28-42, 2013.

[68] M. Darouach and M. Chadli, "Admissibility and control of switched discrete-time singular systems," Systems Science and Control Engineering, vol. 1, no. 1, pp. 43-51, 2013.

[69] M. Basin, P. Shi, and D. Calderon-Alvarez, "Central suboptimal $H_{\infty}$ filter design for nonlinear polynomial systems," International Journal of Adaptive Control and Signal Processing, vol. 23, no. 10, pp. 926-939, 2009.

[70] B. Shen, Z. Wang, H. Shu, and G. Wei, "On nonlinear $H_{\infty}$ filtering for discrete-time stochastic systems with missing measurements," IEEE Transactions on Automatic Control, vol. 53, no. 9, pp. 2170-2180, 2008.

[71] B. Shen, Z. Wang, H. Shu, and G. Wei, "Robust $H_{\infty}$ finitehorizon filtering with randomly occurred nonlinearities and quantization effects," Automatica, vol. 46, no. 11, pp. 1743-1751, 2010.

[72] K. Reif, S. Günther, E. Yaz, and R. Unbehauen, "Stochastic stability of the discrete-time extended Kalman filter," IEEE Transactions on Automatic Control, vol. 44, no. 4, pp. 714-728, 1999.

[73] E. E. Yaz and Y. I. Yaz, "State estimation of uncertain nonlinear stochastic systems with general criteria," Applied Mathematics Letters, vol. 14, no. 5, pp. 605-610, 2001.

[74] X. He, Z. Wang, Y. Liu, and D. Zhou, "Least-squares fault detection and diagnosis for networked sensing systems using adirect state estimation approach," IEEE Transactions on Industrial Informatics, vol. 9, no. 3, pp. 1670-1679, 2013.

[75] X. Li and H. Gao, "Robust finite frequency $H_{\infty}$ filtering for uncertain 2-D systems: the FM model case," Automatica, vol. 49, no. 8, pp. 2446-2452, 2013.

[76] X. Li, H. Gao, and C. Wang, "Generalized Kalman-yakubovichpopov lemma for 2-D FM LSS model," IEEE Transactions on Automatic Control, vol. 57, no. 12, pp. 3090-3103, 2012.

[77] H. Gao and X. Li, " $H_{\infty}$ filtering for discrete-time state-delayed systems with finite frequency specifications," IEEE Transactions on Automatic Control, vol. 56, no. 12, pp. 2935-2941, 2011.

[78] X. Li and H. Gao, "Robust finite frequency $H_{\infty}$ filtering for uncertain 2-D roesser systems," Automatica, vol. 48, no. 6, pp. 1163-1170, 2012.

[79] S. Ding, S. Yin, P. Zhang, and B. Shen, "An integrated design framework of fault-tolerant wireless networked control systems for industrial automatic control applications," IEEE Transactions on Industrial Informatics, vol. 9, no. 1, pp. 462-471, 2013.

[80] S. Yin, S. Ding, A. Haghani, H. Hao, and P. Zhang, "A comparison study of basic data-driven fault diagnosis and processmonitoring methods on the benchmark Tennessee eastman process," Journal of Process Control, vol. 22, no. 9, pp. 1567-1581, 2012.

[81] S. Yin, X. Yang, and H. R. Karimi, "Data-driven adaptive observer for fault diagnosis," Mathematical Problems in Engineering, vol. 2012, Article ID 832836, 21 pages, 2012.

[82] E. Yaz, "On the optimal state estimation of a class of discretetime nonlinear systems," IEEE Transactions on Circuits and Systems, vol. 34, no. 9, pp. 1127-1129, 1987. 
[83] H. Gao, W. Zhan, H. R. Karimi, X. Yang, and S. Yin, "Allocation of actuators and sensors for coupled-adjacent-buildingvibration attenuation," IEEE Transactions on Industrial Electronics, vol. 60, no. 12, pp. 5792-5801, 2013.

[84] H. Gao, W. Sun, and P. Shi, "Robust sampled-data $H_{\infty}$ control for vehicle active suspension systems," IEEE Transactions on Control Systems Technology, vol. 18, no. 1, pp. 238-245, 2010.

[85] H. Gao, X. Meng, T. Chen, and J. Lam, "Stabilization of networked control systems via dynamic output-feedback controllers," SIAM Journal on Control and Optimization, vol. 48, no. 5, pp. 3643-3658, 2009/10.

[86] S. R. Desai and R. Prasad, "A new approach to order reduction using stability equation and big bang big crunch optimization," Systems Science and Control Engineering, vol. 1, no. 1, pp. 20-27, 2013.

[87] H. Dong, Z. Wang, and H. Gao, "Robust $H_{\infty}$ filtering for a class of nonlinear networked systems with multiple stochastic communication delays and packet dropouts," IEEE Transactions on Signal Processing, vol. 58, no. 4, pp. 1957-1966, 2010.

[88] H. Gao and C. Wang, "A delay-dependent approach to robust $H_{\infty}$ filtering for uncertain discrete-time state-delayed systems," IEEE Transactions on Signal Processing, vol. 52, no. 6, pp. 16311640, 2004.

[89] B. Shen, Z. Wang, Y. S. Hung, and G. Chesi, "Distributed $H_{\infty}$ filtering for polynomial nonlinear stochastic systems in sensor networks," IEEE Transactions on Industrial Electronics, vol. 58, no. 5, pp. 1971-1979, 2011.

[90] H. Gao, J. Lam, L. Xie, and C. Wang, "New approach to mixed $\mathrm{H}_{2} / \mathrm{H}_{\infty}$ filtering for polytopic discrete-time systems," IEEE Transactions on Signal Processing, vol. 53, no. 8, pp. 3183-3192, 2005.

[91] H. Rotstein, M. Sznaier, and M. Idan, " $H_{2} / H_{\infty}$ filtering: theory and an aerospace application," in Proceedings of the 1994 American Control Conference, pp. 1791-1795, July 1994.

[92] L. Xie, L. Lu, D. Zhang, and H. Zhang, "Improved robust $H_{2}$ and $H_{\infty}$ filtering for uncertain discrete-time systems," Automatica, vol. 40, no. 5, pp. 873-880, 2004.

[93] M. R. James and I. R. Petersen, "Nonlinear state estimation for uncertain systems with an integral constraint," IEEE Transactions on Signal Processing, vol. 46, no. 11, pp. 2926-2937, 1998.

[94] A. G. Kallapur, I. R. Petersen, and S. G. Anavatti, "A discretetime robust extended Kalman filter for uncertain systems with sum quadratic constraints," IEEE Transactions on Automatic Control, vol. 54, no. 4, pp. 850-854, 2009.

[95] X. Kai, C. Wei, and L. Liu, "Robust extended Kalman filtering for nonlinear systems with stochastic uncertainties," IEEE Transactions on Systems, Man, and Cybernetics A, vol. 40, no. 2, pp. 399405, 2010.

[96] X. Kai, L. Liangdong, and L. Yiwu, "Robust extended Kalman filtering for nonlinear systems with multiplicative noises," Optimal Control Applications \& Methods, vol. 32, no. 1, pp. 47-63, 2011.

[97] Z. Wang, X. Liu, Y. Liu, J. Liang, and V. Vinciotti, “An extended Kalman filtering approach to modelling nonlinear dynamic gene regulatory networks via short gene expression time series," IEEE/ACM Transactions on Computational Biology and Bioinformatics, vol. 6, no. 3, pp. 410-419, 2009.

[98] F. Wang and V. Balakrishnan, "Robust Kalman filters for linear time-varying systems with stochastic parametric uncertainties," IEEE Transactions on Signal Processing, vol. 50, no. 4, pp. 803813, 2002.
[99] B. Shen, Z. Wang, and X. Liu, "Bounded $H_{\infty}$ synchronization and state estimation for discrete time-varying stochastic complex networks over a finite horizon," IEEE Transactions on Neural Networks, vol. 22, no. 1, pp. 145-157, 2011.

[100] A. Ray, "Performance evaluation of medium access control protocols for distributed digital avionics," ASME Journal of Dynamic Systems, Measurement and Control, vol. 109, no. 4, pp. 370377, 1987.

[101] J.-A. Guu and C.-H. Wei, “Tracking technique for manoeuvring target with correlated measurement noises and unknown parameters," IEE Proceedings F-Radar and Signal Processing, vol. 138, no. 3, pp. 278-288, 1991.

[102] E. Song, Y. Zhu, and Z. You, “The Kalman type recursive state estimator with a finite-step correlated process noises," in Proceedings of the IEEE International Conference on Automation and Logistics (ICAL '08), pp. 196-200, Qingdao, China, September 2008 .

[103] D. Simon, Optimal State Estimation: Kalman, $H_{\infty}$, and Nonlinear Approaches, John Wiley \& Sons, New York, NY, USA, 2006.

[104] A. Fu, Y. Zhu, and E. Song, "The optimal Kalman type state estimator with multi-step correlated process and measurement noises," in Proceedings of the International Conference on Embedded Software and Systems (ICESS '08), pp. 215-220, Sichuan, China, July 2008.

[105] E. Song, Y. Zhu, J. Zhou, and Z. You, "Optimal Kalman filtering fusion with cross-correlated sensor noises," Automatica, vol. 43, no. 8, pp. 1450-1456, 2007.

[106] J. Feng, Z. Wang, and M. Zeng, "Optimal robust non-fragile Kalman-type recursive filtering with finite-step autocorrelated noises and multiple packet dropouts," Aerospace Science and Technology, vol. 15, no. 6, pp. 486-494, 2011.

[107] M. Darouach, M. Zasadzinski, and M. Boutayeb, "Extension of minimum variance estimation for systems with unknown inputs," Automatica, vol. 39, no. 5, pp. 867-876, 2003.

[108] J. Chandrasekar, D. S. Bernstein, O. Barrero, and B. L. R. De Moor, "Kalman filtering with constrained output injection," International Journal of Control, vol. 80, no. 12, pp. 1863-1879, 2007.

[109] S. J. Julier and J. J. LaViola, Jr., "On Kalman filtering with nonlinear equality constraints," IEEE Transactions on Signal Processing, vol. 55, no. 6, pp. 2774-2784, 2007.

[110] B. O. S. Teixeira, J. Chandrasekar, H. J. Palanthandalam-Madapusi, L. A. B. Tôrres, L. A. Aguirre, and D. S. Bernstein, "Gainconstrained Kalman filtering for linear and nonlinear systems," IEEE Transactions on Signal Processing, vol. 56, no. 9, pp. 41134123, 2008.

[111] J. M. Del Rincón, D. Makris, C. O. Uruñuela, and J.-C. Nebel, "Tracking human position and lower body parts using Kalman and particle filters constrained by human biomechanics," IEEE Transactions on Systems, Man, and Cybernetics B, vol. 41, no. 1, pp. 26-37, 2011.

[112] S. Kolås, B. A. Foss, and T. S. Schei, "Constrained nonlinear state estimation based on the UKF approach," Computers and Chemical Engineering, vol. 33, no. 8, pp. 1386-1401, 2009.

[113] C. Yang and E. Blasch, "Kalman filtering with nonlinear state constraints," in Proceedings of the 9th International Conference on Information Fusion, Seattle, Wash, USA, July 2006.

[114] S. Yin, H. Luo, and S. Ding, "Real-time implementation of faulttolerant control systems with performance optimization," IEEE Transactions on Industrial Electronics, vol. 61, no. 5, pp. 24022411, 2014. 
[115] I. Yaesh, S. Boyarski, and U. Shaked, "Probability-guaranteed robust $H_{\infty}$ performance analysis," in Proceedings of the 15th IFAC Congress, Barcelona, Spain, 2002.

[116] S. Boyarski and U. Shaked, "Discrete-time $H_{\infty}$ and $H_{2}$ control with structured disturbances and probability-relaxed requirements," International Journal of Control, vol. 77, no. 14, pp. 12431259, 2004.

[117] S. Boyarski and U. Shaked, "Robust $H_{\infty}$ control design for best mean performance over an uncertain-parameters box," System \& Control Letters, vol. 54, no. 6, pp. 585-595, 2005.

[118] S. Boyarski and U. Shaked, "Probability-guaranteed robust fullorder and reduced-order $H_{\infty}$-filtering," in Proceedings of the IFAC SSSC, Foz do Iguassu, Brazil, 2007.

[119] I. Yaesh, S. Boyarski, and U. Shaked, "Probability-guaranteed robust $H_{\infty}$ performance analysis and state-feedback design," Systems \& Control Letters, vol. 48, no. 5, pp. 351-364, 2003.

[120] L. Wu, P. Shi, and H. Gao, "State estimation and sliding-mode control of Markovian jump singular systems," Institute of Electrical and Electronics Engineers, vol. 55, no. 5, pp. 1213-1219, 2010.

[121] Y. Xia, G.-P. Liu, P. Shi, J. Chen, and D. Rees, "Robust delaydependent sliding mode control for uncertain time-delay systems," International Journal of Robust and Nonlinear Control, vol. 18, no. 11, pp. 1142-1161, 2008.

[122] X. Yu and M. Zhihong, "Fast terminal sliding-mode control design for nonlinear dynamical systems," IEEE Transactions on Circuits and Systems I, vol. 49, no. 2, pp. 261-264, 2002.

[123] G. Foo and M. F. Rahman, "Sensorless sliding-mode MTPA control of an IPM synchronous motor drive using a slidingmode observer and HF signal injection," IEEE Transactions on Industrial Electronics, vol. 57, no. 4, pp. 1270-1278, 2010.

[124] T. Orlowska-Kowalska, M. Dybkowski, and K. Szabat, "Adaptive sliding-mode neuro-fuzzy control of the two-mass induction motor drive without mechanical sensors," IEEE Transactions on Industrial Electronics, vol. 57, no. 2, pp. 553-564, 2010.

[125] B. K. Kim, W. K. Chung, and K. Ohba, "Design and performance tuning of sliding-mode controller for high-speed and highaccuracy positioning systems in disturbance observer framework," IEEE Transactions on Industrial Electronics, vol. 56, no. 10, pp. 3798-3809, 2009.

[126] C. Pukdeboon, A. S. I. Zinober, and M.-W. L. Thein, "Quasicontinuous higher order sliding-mode controllers for spacecraft-attitude-tracking maneuvers," IEEE Transactions on Industrial Electronics, vol. 57, no. 4, pp. 1436-1444, 2010.

[127] H. H. Choi, "LMI-based sliding surface design for integral sliding mode control of mismatched uncertain systems," IEEE Transactions on Automatic Control, vol. 52, no. 4, pp. 736-742, 2007.

[128] L. Wu and W. X. Zheng, "Passivity-based sliding mode control of uncertain singular time-delay systems," Automatica, vol. 45, no. 9, pp. 2120-2127, 2009.

[129] Y. Niu, D. W. C. Ho, and X. Wang, "Sliding mode control for Itô stochastic systems with Markovian switching," Automatica, vol. 43, no. 10, pp. 1784-1790, 2007.

[130] P. Shi, Y. Xia, G. P. Liu, and D. Rees, "On designing of slidingmode control for stochastic jump systems," IEEE Transactions on Automatic Control, vol. 51, no. 1, pp. 97-103, 2006.

[131] K. Abidi, J.-X. Xu, and Y. Xinghuo, "On the discrete-time integral sliding-mode control," IEEE Transactions on Automatic Control, vol. 52, no. 4, pp. 709-715, 2007.

[132] A. Bartoszewicz, "Discrete-time quasi-sliding-mode control strategies," IEEE Transactions on Industrial Electronics, vol. 45, no. 4, pp. 633-637, 1998.
[133] W. Gao, Y. Wang, and A. Homaifa, "Discrete-time variable structure control systems," IEEE Transactions on Industrial Electronics, vol. 42, no. 2, pp. 117-122, 1995.

[134] N. O. Lai, C. Edwards, and S. K. Spurgeon, "Discrete output feedback sliding-mode control with integral action," International Journal of Robust and Nonlinear Control, vol. 16, no. 1, pp. 21-43, 2006.

[135] N. O. Lai, C. Edwards, and S. K. Spurgeon, "On output tracking using dynamic output feedback discrete-time sliding-mode controllers," IEEE Transactions on Automatic Controll, vol. 52, no. 10, pp. 1975-1981, 2007.

[136] X. G. Yan, S. K. Spurgeon, and C. Edwards, "Static output feedback sliding mode control for time-varying delay systems with time-delayed nonlinear disturbances," International Journal of Robust and Nonlinear Control, vol. 20, no. 7, pp. 777-788, 2010.

[137] X.-G. Yan, S. K. Spurgeon, and C. Edwards, "Decentralised sliding mode control for nonminimum phase interconnected systems based on a reduced-order compensator," Automatica, vol. 42, no. 10, pp. 1821-1828, 2006.

[138] Y. Xia, M. Fu, P. Shi, and M. Wang, "Robust sliding mode control for uncertain discrete-time systems with time delay," IET Control Theory \& Applications, vol. 4, no. 4, pp. 613-624, 2010.

[139] L. F. Ma, Z. D. Wang, and Z. Guo, "Robust $\mathrm{H}_{2}$ sliding mode control for non-linear discrete-time stochastic systems," IET Control Theory \& Applications, vol. 3, no. 11, pp. 1537-1546, 2009.

[140] L. Ma, Z. Wang, Y. Niu, Y. Bo, and Z. Guo, "Sliding mode control for a class of nonlinear discrete-time networked systems with multiple stochastic communication delays," International Journal of Systems Science, vol. 42, no. 4, pp. 661-672, 2011.

[141] C. Lascu, I. Boldea, and F. Blaabjerg, "A class of speed-sensorless sliding-mode observers for high-performance induction motor drives," IEEE Transactions on Industrial Electronics, vol. 56, no. 9, pp. 3394-3403, 2009.

[142] C. P. Tan, X. Yu, and Z. Man, "Terminal sliding mode observers for a class of nonlinear systems," Automatica, vol. 46, no. 8, pp. 1401-1404, 2010.

[143] X.-G. Yan and C. Edwards, "Nonlinear robust fault reconstruction and estimation using a sliding mode observer," Automatica, vol. 43, no. 9, pp. 1605-1614, 2007.

[144] F. J. Bejarano and L. Fridman, "High order sliding mode observer for linear systems with unbounded unknown inputs," International Journal of Control, vol. 83, no. 9, pp. 1920-1929, 2010.

[145] C. Edwards and S. K. Spurgeon, "Sliding mode stabilization of uncertain systems using only output information," International Journal of Control, vol. 62, no. 5, pp. 1129-1144, 1995.

[146] C. Edwards, S. K. Spurgeon, and R. J. Patton, "Sliding mode observers for fault detection and isolation," Automatica, vol. 36, no. 4, pp. 541-553, 2000.

[147] B. Jiang, M. Staroswiecki, and V. Cocquempot, "Fault estimation in nonlinear uncertain systems using robust sliding-mode observers," IEE Proceedings on Control Theory and Applications, vol. 151, no. 1, pp. 29-37, 2004.

[148] C. P. Tan and C. Edwards, "Robust fault reconstruction in uncertain linear systems using multiple sliding mode observers in cascade," IEEE Transactions on Automatic Control, vol. 55, no. 4, pp. 855-867, 2010.

[149] S. K. Spurgeon, "Sliding mode observers: a survey," International Journal of Systems Science, vol. 39, no. 8, pp. 751-764, 2008.

[150] K. C. Veluvolu and Y. C. Soh, "Discrete-time sliding-mode state and unknown input estimations for nonlinear systems," IEEE Transactions on Industrial Electronics, vol. 56, no. 9, pp. 34433452, 2009. 
[151] R. Raoufi, H. J. Marquez, and A. S. I. Zinober, " $H_{\infty}$ sliding mode observers for uncertain nonlinear Lipschitz systems with fault estimation synthesis," International Journal of Robust and Nonlinear Control, vol. 20, no. 16, pp. 1785-1801, 2010.

[152] K. C. Veluvolu, Y. C. Soh, and W. Cao, "Robust discrete-time nonlinear sliding mode state estimation of uncertain nonlinear systems," International Journal of Robust and Nonlinear Control, vol. 17, no. 9, pp. 803-828, 2007.

[153] J. Hu, Z. Wang, H. Gao, and L. K. Stergioulas, "Extended Kalman filtering with stochastic nonlinearities and multiple missing measurements," Automatica, vol. 48, no. 9, pp. 2007-2015, 2012.

[154] J. Hu, Z. Wang, B. Shen, and H. Gao, "Quantised recursive filtering for a class of nonlinear systems with multiplicative noises and missing measurements," International Journal of Control, vol. 86, no. 4, pp. 650-663, 2013.

[155] J. Hu, Z. Wang, and H. Gao, "Recursive filtering with random parameter matrices, multiple fading measurements and correlated noises," Automatica, vol. 49, no. 11, pp. 3440-3448, 2013.

[156] J. Hu, Z. Wang, B. Shen, and H. Gao, "Gain-constrained recursive filtering with stochastic nonlinearities and probabilistic sensor delays," IEEE Transactions on Signal Processing, vol. 61, no. 5, pp. 1230-1238, 2013.

[157] J. Hu, Z. Wang, H. Gao, and L. K. Stergioulas, "Probabilityguaranteed $H_{\infty}$ finite-horizon filtering for a class of nonlinear time-varying systems with sensor saturations," Systems \& Control Letters, vol. 61, no. 4, pp. 477-484, 2012.

[158] J. Hu, Z. Wang, Y. Niu, and L. K. Stergioulas, “ $H_{\infty}$ sliding mode observer design for a class of nonlinear discrete time-delay systems: a delay-fractioning approach," International Journal of Robust and Nonlinear Control, vol. 22, no. 16, pp. 1806-1826, 2012.

[159] J. Hu, Z. Wang, and H. Gao, "A delay fractioning approach to robust sliding mode control for discrete-time stochastic systems with randomly occurring non-linearities," IMA Journal of Mathematical Control and Information, vol. 28, no. 3, pp. 345363, 2011.

[160] J. Hu, Z. Wang, H. Gao, and L. K. Stergioulas, "Robust $H_{\infty}$ sliding mode control for discrete time-delay systems with stochastic nonlinearities," Journal of the Franklin Institute, vol. 349, no. 4, pp. 1459-1479, 2012.

[161] J. Hu, Z. Wang, H. Gao, and L. K. Stergioulas, "Robust sliding mode control for discrete stochastic systems with mixed time delays, randomly occurring uncertainties, and randomly occurring nonlinearities," IEEE Transactions on Industrial Electronics, vol. 59, no. 7, pp. 3008-3015, 2012.

[162] J. Hu, Z. Wang, Y. Niu, and H. Gao, "Sliding mode control for uncertain discrete-time systems withparameters and mixed delays," Journal of the Franklin Institute. 


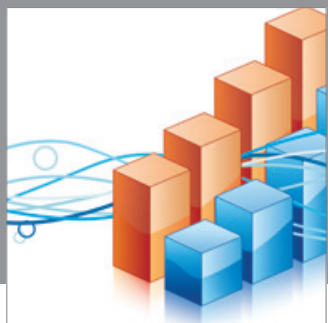

Advances in

Operations Research

mansans

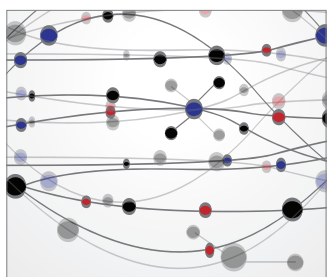

The Scientific World Journal
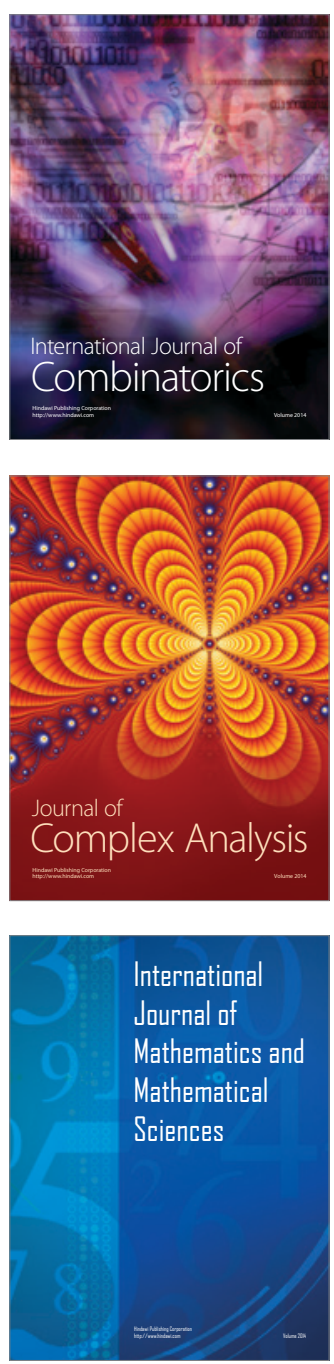
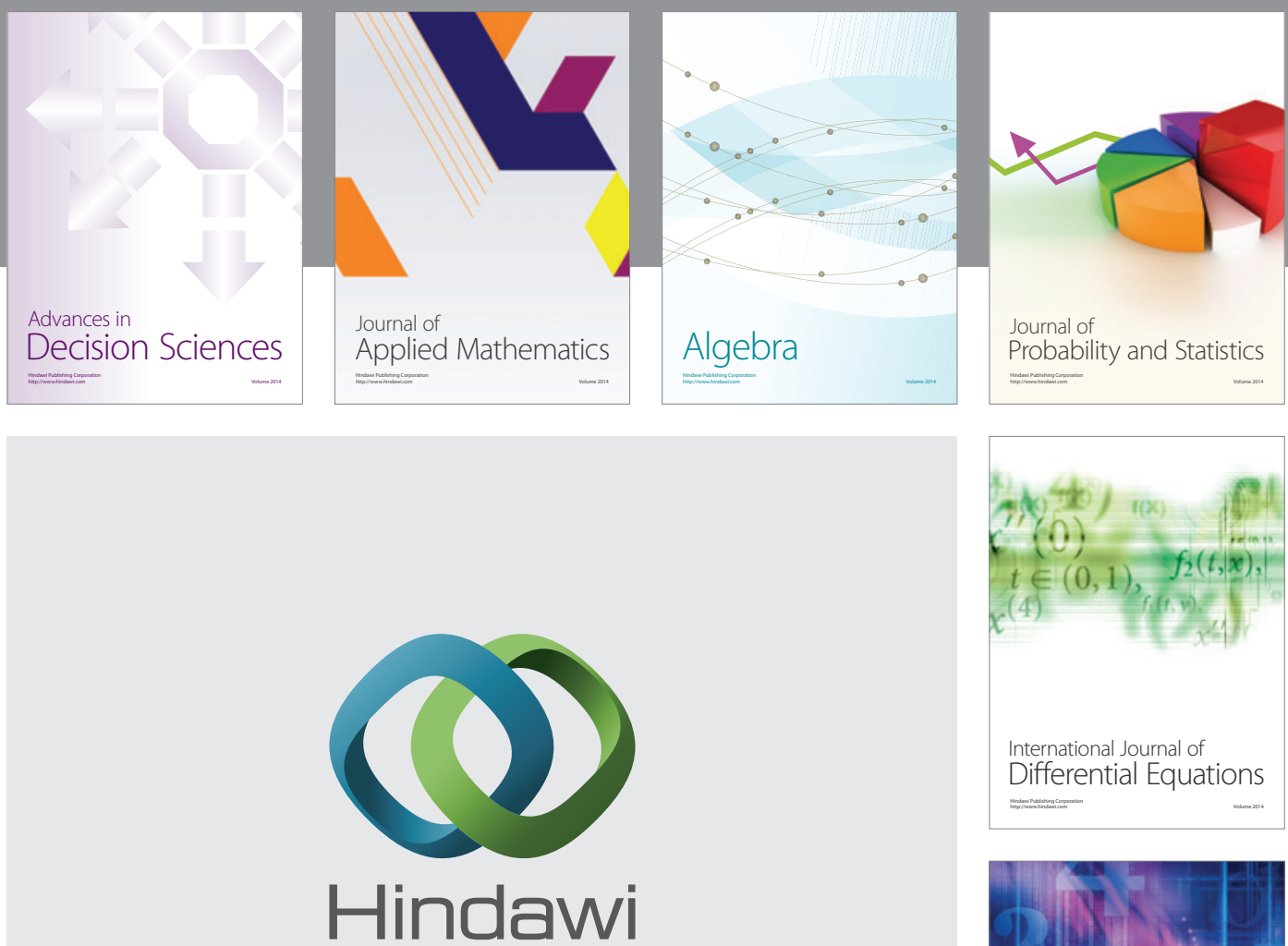

Submit your manuscripts at http://www.hindawi.com
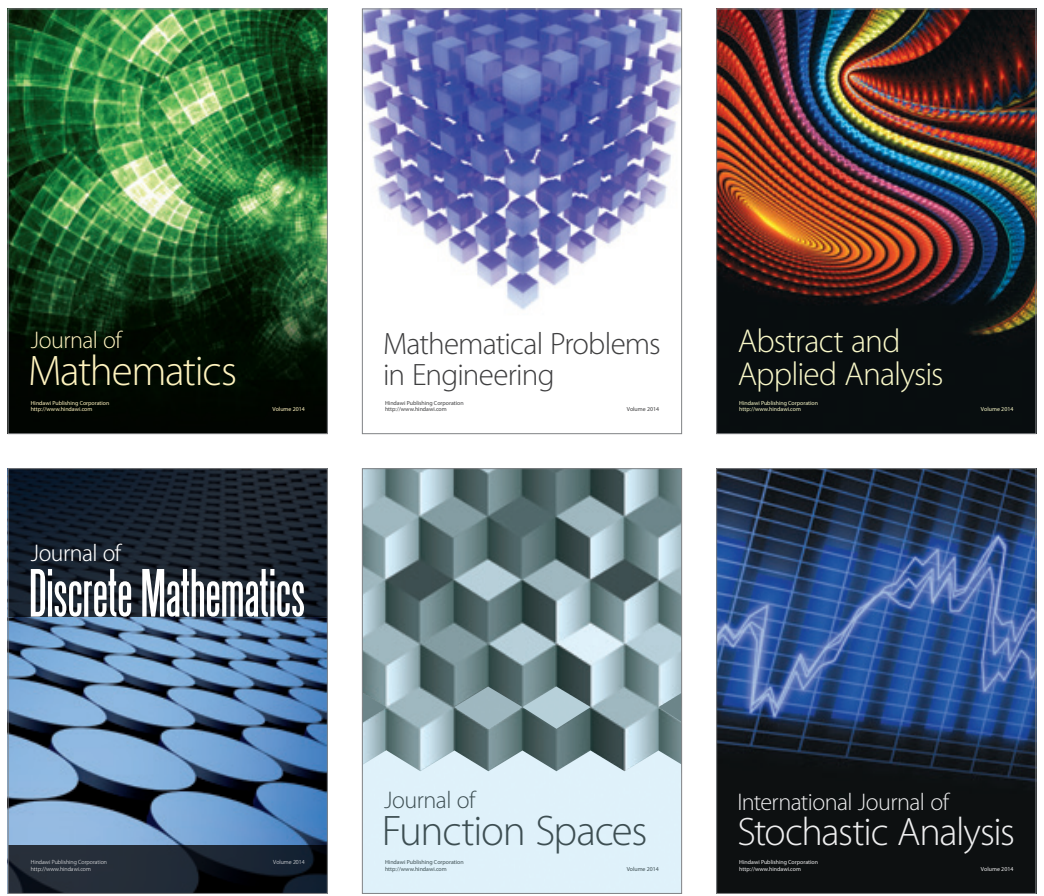

Journal of

Function Spaces

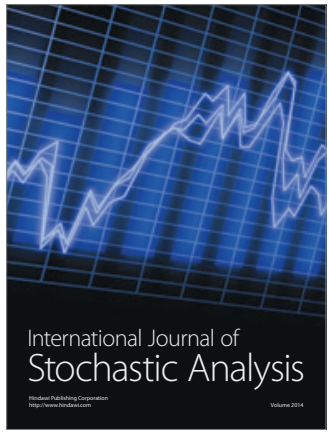

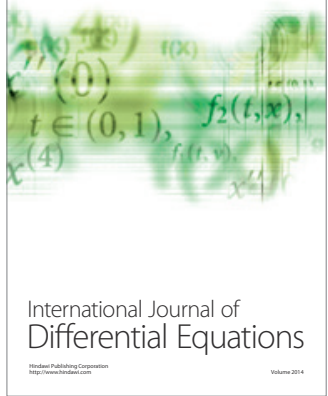
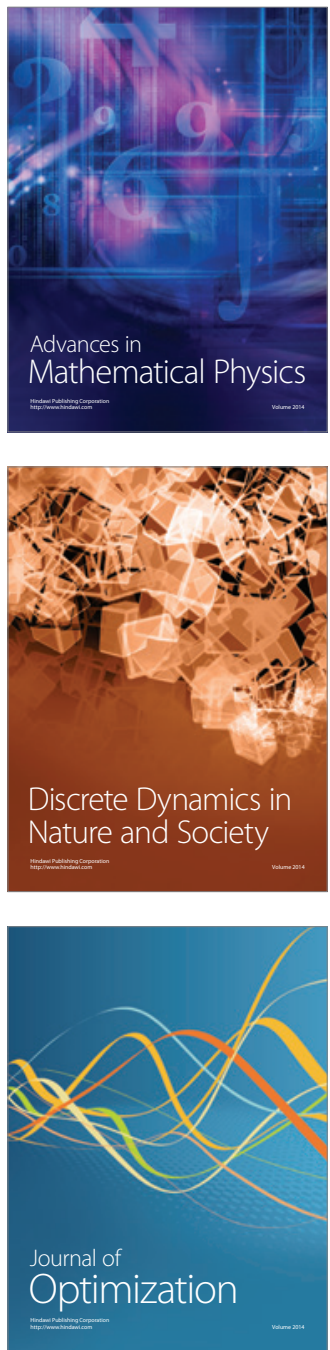